\title{
Mistreatment of women in public health facilities of Ethiopia
}

Ephrem D. Sheferaw ${ }^{1,2^{*}} \mathbb{D}$, Young-Mi Kim ${ }^{2,3}$, Thomas van den Akker ${ }^{4}$ and Jelle Stekelenburg ${ }^{2,5}$

\begin{abstract}
Background: Recent evidence suggests that mistreatment of women during childbirth is a global challenge facing health care systems. This study seeks to explore the prevalence of mistreatment of women in public health facilities of Ethiopia, and identify associated factors.

Methods: A two-stage cross sectional sampling design was used to select institutions and women. The study was conducted in hospitals and health centers across four Ethiopian regions. Quantitative data were collected from postpartum women. Mistreatment was measured using four domains: (1) physical abuse, (2) verbal abuse, (3) failure to meet professional standards of care, and (4) poor rapport between women and providers. Percentages of mistreatment and odds ratios for the association between its presence and institutional and socio demographic characteristics of women were calculated using bivariate and multivariable logistic regression modeling.

Results: A total of 379 women were interviewed, of whom 281 (74\%) reported any mistreatment. Physical and verbal abuse were reported by $7(2 \%)$ and 31 (8\%) women interviewed respectively. Failure to meet professional standards of care and poor rapport between women and providers were reported by 111 (29\%) and 274 (72\%) women interviewed respectively.

Multivariable logistic regression analysis revealed that the odds of reporting mistreatment were higher among women with four or more previous births ( $\mathrm{aOR}=3.3695 \% \mathrm{Cl} 1.22,9.23, p=0.019)$ compared to women with no previous childbirth, Muslim women ( $\mathrm{aOR}=3.3095 \% \mathrm{Cl} 1.4,7.77, p=0.006)$ and women interviewed in facilities with less than 17 births per MNH staff in a month (aOR = 3.6395\%Cl 1.9,6.93, $p<0.001)$. However, the odds of reporting mistreatment were lower among women aged 35 and older $(\mathrm{aOR}=0.2295 \% \mathrm{Cl} 0.06,0.73, p=0.014)$ and among women interviewed between 8 and 42 days after childbirth ( $\mathrm{aOR}=0.3795 \% \mathrm{Cl} 0.15,0.9, p=0.028)$.
\end{abstract}

Conclusion: Mistreatment during childbirth in Ethiopia is commonly reported. Health workers need to consider provision of individualized care for women and monitor their experiences in order to adjust quality of their services.

Keywords: Mistreatment, Disrespect and abuse, Respectful maternity care, Ethiopia

\section{Plain English summary}

Recent evidence suggests that mistreatment of women during childbirth is a global challenge facing health care systems. This study seeks to explore the level of mistreatment of women in public health facilities in Ethiopia and identify associated factors. The study was conducted in hospitals and health centers across four

\footnotetext{
* Correspondence: ephremdan@gmail.com; e.d.sheferaw@umcg.nl; Ephrem.Daniel@jhpiego.org

1Jhpiego Ethiopia, Addis Ababa, Ethiopia

${ }^{2}$ Department of Health Sciences, University of Groningen, University Medical Centre Groningen, Global Health, Antonius Deusinglaan 1, 9713, AV,

Groningen, The Netherlands

Full list of author information is available at the end of the article
}

Ethiopian regions. Quantitative data were collected from postpartum women. Mistreatment was measured using four domains: (1) physical abuse, (2) verbal abuse, (3) failure to meet professional standards of care, and (4) poor rapport between women and providers. A total of 379 women were interviewed, of whom 281 (74\%) reported any mistreatment. Physical and verbal abuse were reported by $7(2 \%)$ and $31(8 \%)$ women interviewed respectively. Failure to meet professional standards of care and poor rapport between women and providers were reported by $111(29 \%)$ and $274(72 \%)$ women interviewed respectively. The odds of reporting mistreatment were higher among women aged less than 25 compared to

(c) The Author(s). 2019 Open Access This article is distributed under the terms of the Creative Commons Attribution 4.0 International License (http://creativecommons.org/licenses/by/4.0/), which permits unrestricted use, distribution, and 
women aged 35 and above, those with four or more previous births compared to no previous birth, and also in those who gave birth in facilities with fewer (less than 17) births per $\mathrm{MNH}$ staff in a month. Mistreatment during childbirth in Ethiopia is commonly reported. Health workers need to consider provision of individualized care for women and monitor their experience in order to adjust quality of their services.

\section{Introduction}

The third Sustainable Development Goal aims to reduce the maternal mortality ratio (MMR) to below 70 per 100,000 live births in all countries by 2030 [1]. Ensuring access to skilled birth attendance in well-functioning health facilities is a widely-accepted strategy to prevent maternal mortality [2] . Recent studies in lowand middle-income countries on experiences of women during childbirth in health facilities have revealed unacceptable practices including disrespectful, abusive or neglectful treatment [3-6]. These experiences of mistreatment are identified as reasons for low institutional birth rates [7-10].

Ethiopia saw a dramatic decline in MMR from 1400 to 420 per 100,000 live births between 1990 and 2013 [11]. Despite this progress, the MMR remains unacceptably high. Ensuring access to maternity care by skilled providers working in a functional health facility forms the basis of the strategy formulated by the Federal Ministry of Health of Ethiopia to reduce maternal mortality. As part of this strategy, a large number of health centers and hospitals were built and staffed by essential health care providers over the past decade. Coverage of births attended in health facilities increased from 7 to $62 \%$ between 2007 and 2015 [12, 13]. The Ethiopian health system is structured into three tiers: primary, secondary and tertiary levels. The primary care level includes primary hospitals, health centers and health posts. The secondary level includes general hospitals and the tertiary level comprises specialized hospitals [14]. Most of the expansion in the health sector over the past decade occurred at the primary level $[15,16]$.

Although the Ministry of Health promotes the provision of compassionate and respectful care in these facilities, which includes individualized and culturally sensitive care for all women [17], some studies in Ethiopia indicate that physical and verbal abuse, non-consented care and lack of consideration of cultural practices related to childbirth by health workers may take place, possibly compounded by the increasing pressure on the health system due to the growing number of facility births $[10,18]$. In this way, disrespectful and abusive behaviors by health providers during childbirth, which are known to be a significant barrier to increasing facility based births, could be a threat to the gains made in coverage of skilled birth attendance and to reductions of maternal mortality $[19,20]$.

Understanding the prevalence of mistreatment in Ethiopian maternity care facilities is therefore critical. Studies to date are limited in number, conducted in a limited geographic area or fail to apply similar definitions. In a previous study in a hospital and two health centers in Addis Ababa, 78\% of respondents experienced one or more categories of disrespect and abuse including violation of the right to information, informed consent, and choice of position during childbirth [21] A study in four health centers in Amhara and SNNP regions, 21.1\% of women reported occurrence of any disrespect and abuse [22]. A study using provider-client observations in 28 facilities across the four most populous regions in Ethiopia showed that $36 \%$ of women experienced any mistreatment [23]. On the other hand, a community based assessment in Tigray region reported that $22 \%$ of women experience mistreatment during childbirth in health facilities [24].

This study aimed to generate evidence on the prevalence of mistreatment of women in public health facilities as reported by women in Ethiopia and identify factors that may contribute to such mistreatment.

\section{Materials and methods \\ Design}

The study used a cross-sectional two-stage sampling design with quantitative data collection methods.

\section{Setting}

The study was conducted in June 2016, in 38 public hospitals and health centers across 4 regions in EthiopiaOromia, Amhara, Southern Nations Nationalities and Peoples (SNNP) and Tigray. Interviews were conducted in public hospitals and health centers in both urban and rural areas.

\section{Data collection}

Twelve data collectors, who were external to and clearly expressed not to be part of facility staff with a minimum of a BSc degree qualification, conducted the recruitment in postnatal and immunization units. Data collectors interviewed women in a private area within the premises of the health facilities immediately after childbirth or after women attended immunization and postnatal care services. Quantitative data on health facility policy were collected from facility managers and maternity unit leaders.

Four supervisors and two coordinators from the Maternal and Child Survival Program (MCSP) and the Ministry of Health coordinated the data collection process. Data collectors were external to the health facilities assessed. Study coordinators ensured that data collectors were competent in the application of the 
standardized tools for data collection. All data collectors attended a three-day training workshop in Addis Ababa to ensure that they were oriented to scientific and ethical standards.

\section{Participants}

Maternity unit leads were interviewed about facility-related policies such as allowing non-harmful cultural practices during childbirth in health facilities and allowing women to choose their preferred birthing position. Women who had used skilled birth attendance services in public health facilities from 6 hours to 3 months prior to the start of data collection were included and interviewed about their birthing experiences.

\section{Data sources}

Since no validated tool for measuring mistreatment of women at the time of data collection was present in the literature, the study team utilized a structured interview tool for postpartum women adopted from the Population Council Heshima project that was piloted in Kenya and previously applied in Kenya, Tanzania and Ethiopia [16, 25]. The exit interview tool captured four of the seven types of mistreatment. These are: 1. Physical abuse, 2. Verbal abuse, 3. Failure to meet professional standard of care and 4. Poor rapport between women and providers [26]. For facility-related policy assessment, a survey tool was developed by the study team. The tools used are included in Additional files 1 and 2.

The outcome variable was any mistreatment, measured as a binary (yes/no) variable, which was defined as being present if any of the four categories of mistreatment was reported. Physical abuse included hitting, slapping or pinching. Verbal abuse included shouting, scolding, threatening to take women into the operating theatre or addressing women using insulting names. Failure to meet standards of care included neglecting women when they needed care at some point during labor and childbirth, ignoring women's requests for pain relief, providing treatment without consent and providing care that violated privacy of women. Poor rapport between women and providers included not greeting women, not explaining the labor progress, not responding to women's questions in a polite manner, not encouraging women to move around freely, not allowing women to bring a companion, not allowing women to give birth in their preferred birth position and not offering hot drinks or food after childbirth. Based on literature review and expert judgment of the investigators the following explanatory variables were assessed: socio demographic characteristics of women including age, educational status, marital status, employment status, number of previous births, religion, residence, antenatal care, follow-up visit, time of childbirth and interval between time of interview and childbirth. Similarly, facility-related explanatory variables such as facility type, a policy of organizing facility visits for pregnant women, a policy of reporting providers' misconduct, number of births per maternity care worker, and the proportion of maternity care providers trained in BEmONC were assessed.

\section{Sampling}

The sample size calculation for the client interview used assumptions of $95 \%$ level of confidence, variability of attributes related to Disrespect and Abuse (D\&A) with a proportion of 0.14 (using the MCHIP study estimate of self-reported D\&A prevalence in the same regions in 2014 [27]), and an anticipated non-response rate of $10 \%$, plus or minus 4 percentage points of relative error (which is equivalent to $0.56 \%$ absolute margin of error), $10 \%$ non-response rate and using Design Effect (DE) of 1.2 since there were no estimates of DE from previous studies [28]. Using these statistical parameters, the total number of participants required for client interviews was 382. However, we planned to interview 380 women by allocating an equal number of ten clients from each facility using the strategy described below.

Sampling was conducted in two stages. First, 85 hospitals and 751 health centers that have an average of 60 births per month from the national health management information systems report were listed as sampling frame. These facilities were categorized into two groups, high volume and low volume facilities, using the median number of attended births per month; using power allocation 11 hospitals and 27 health centers (19 from high volume and 19 from low volume) were selected randomly using a systematic random sampling approach. In the second stage of sampling, 10 women from each selected facility were selected randomly in postnatal and immunization units. All clients that fulfilled inclusion criteria, having attended childbirth services in selected health facilities between 6 hours to 3 months prior to the interview were invited.

\section{Data analysis}

The study team leader supervised data entry and cleaning. Data were entered using EPI data software and exported to Stata 15.0 for further statistical analysis [29]. Before data analysis was started, the presence of extreme values was assessed using standardized scores of independent variables. Similarly, the effect of influential cases and leverage cases were assessed using residual analysis.

Frequencies and percentages of client background characteristics and birth experiences, availability of facility policies related to respectful maternity care (RMC) and components of mistreatment disaggregated by health center and hospital were calculated. Bivariate 
analysis was performed to detect statistically significant associations between the outcome variable (mistreatment of women) and explanatory variables in the study group. Multivariable multilevel logistic regression analysis was used to identify factors associated with mistreatment of women. A P-value less than 0.25 in the binary analysis was used as the criterion to include a variable into the multivariable regression model. The explanatory variables included in the binary and multivariable regression were women's individual characteristics (age, education level, religion, marital status, parity, residence, time of birth and presence of complications at birth). Health facility characteristics recorded were proportion of maternal and child health care $(\mathrm{MCH})$ providers trained in Basic Emergency Maternal Obstetric and Newborn Care (BEmONC), number of birth per $\mathrm{MCH}$ provider, availability of a policy of providing a tour for pregnant women around the maternity unit and availability of a policy of anonymous reporting of providers' misconduct. The effect sizes of individual and facility level factors on the reported mistreatment of women were expressed in crude odds ratios (OR) and adjusted odds ratios (aOR), with their respective 95\% Confidence Intervals (CI).

\section{Ethical considerations}

This study was approved by the Johns Hopkins Bloomberg School of Public Health Institutional Review Board in Baltimore, Maryland, USA. The institutional review board ruled the protocol exempt from review under 45 CFR 46.101(b)(5). The study was further approved by the national Ministry of Health and the regional health bureaus of Amhara, Oromia, Tigray and SNNPR. Structured interviews of women were conducted in a private area after receiving oral informed consent. The client consent forms were translated into and administered in the Amharic, Tigrigna and Afan Oromo languages.

\section{Results}

A total of 379 women were interviewed in 27 health centers and 11 hospitals in Oromia, Amhara, Tigray and SNNPR regions. Among 380 women we planned to interview, we could not interview three women in one of the hospitals because of temporary civil unrest in the town and an additional two women were interviewed in two other health centers.

A majority, 73 of the 107 (68\%) participants interviewed in hospitals were urban residents compared to only 121 of the $272(44 \%)$ participants interviewed in health centers. The percentage of women interviewed in the first week after childbirth was higher in health centers compared to hospitals (41\% vs. $11 \%$ ) (Table 1 ).

Table 2 describes policies on RMC in the facilities. Health facility managers and maternity unit leaders reported existence of most of the policies on RMC. The least reported policies were allowing non-harmful cultural rituals in health facilities (reported in 23 (85\%) health centers and 4 (36\%) hospitals) and allowing women a choice of birthing position (in 20 (74\%) health centers and 6 (55\%) hospitals).

Table 3 describes the level of self-reported mistreatment of women. Overall, three out of four women (74\%, $n=281)$ reported any mistreatment during their latest childbirth experience in health facilities, with women in hospitals and health centers reporting 87 and $69 \%$ respectively.).

Physical abuse and verbal abuse were the least prevalent experiences of mistreatment reported by seven (2\%) and $31(8 \%)$ women respectively. Failure to meet standards of care (neglect, non-consented care, non-confidential care and pain relief ignored) was reported by $29 \%$. On the other hand, poor rapport between women and providers was the most prevalent form of mistreatment, reported by $72 \%$ of the women. Standardized scores of independent variables confirmed that there were no extreme values. Similarly, residual analysis suggested the absence of influential and leverage cases.

Table 4 describes bivariate and multivariable logistic regression analysis of possible predictors of mistreatment of women.

In the bivariate analysis, compared to women interviewed in health centers those interviewed in hospitals $(\mathrm{OR}=9.6395 \% \mathrm{CI} 1.25,74.26, p=0.03)$ were more likely to report mistreatment. Women who gave birth in health facilities with less than 17 births per month $(\mathrm{OR}=5.46,0.97,30.62, p=0.054)$ and with no policy of a facility tour for pregnant women (OR $=6.7495 \%$ CI $1.23,37.02 ; p=0.028)$ were more likely to report mistreatment.

In a multivariable logistic regression analysis, the odds of reporting mistreatment were higher among women with four or more previous births $(\mathrm{aOR}=3.3695 \% \mathrm{CI}$ $1.22,9.23, p=0.019)$ compared to women with no previous childbirth, among Muslim women $(\mathrm{aOR}=3.30$ 95\%CI 1.4, 7.77, $p=0.006$ ) compared to Orthodox Christians and among women interviewed in facilities with less than 17 births per MNH staff in a month $(\mathrm{aOR}=$ $3.6395 \%$ CI 1.9, 6.93, $p<0.001$ ). However, the odds of reporting mistreatment were lower among women aged 35 and older compared to those younger than 25 (aOR = $0.2295 \%$ CI $0.06,0.73 p=0.014$ ) and among women interviewed between 8 and 42 days after childbirth $(\mathrm{aOR}=0.37$ 95\% CI 0.15, $0.9 p=0.028)$.

\section{Discussion}

This study assessed the level of mistreatment of women during childbirth in 38 randomly selected health facilities with high and low case load across Tigray, Amhara, 
Table 1 Background characteristics and birth experience of respondents

\begin{tabular}{|c|c|c|c|c|c|c|}
\hline \multirow[t]{2}{*}{ Variables } & \multicolumn{2}{|c|}{ Total $(N=379)$} & \multicolumn{2}{|c|}{ Health Centers $(N=272)$} & \multicolumn{2}{|c|}{ Hospitals $(N=107)$} \\
\hline & $\bar{N}$ & $\overline{\text { Percent }}$ & $\bar{N}$ & Percent & $\bar{N}$ & Percent \\
\hline \multicolumn{7}{|l|}{ Residence Location } \\
\hline Urban & 194 & 51 & 121 & 44 & 73 & 68 \\
\hline Rural & 185 & 49 & 151 & 56 & 34 & 32 \\
\hline \multicolumn{7}{|l|}{ Residence region } \\
\hline Tigray & 40 & 11 & 20 & 7 & 20 & 19 \\
\hline Amhara & 100 & 26 & 70 & 26 & 30 & 28 \\
\hline Oromia & 139 & 37 & 112 & 41 & 27 & 25 \\
\hline SNNPR & 100 & 26 & 70 & 26 & 30 & 28 \\
\hline \multicolumn{7}{|l|}{ Age } \\
\hline$<25$ & 167 & 44 & 116 & 43 & 51 & 48 \\
\hline $25-34$ & 177 & 47 & 129 & 48 & 48 & 45 \\
\hline $35+$ & 34 & 9 & 26 & 10 & 8 & 7 \\
\hline Education - ever attended school & 278 & 73 & 192 & 71 & 86 & 80 \\
\hline \multicolumn{7}{|l|}{ Highest level of school attended } \\
\hline Informal education/can read and write & 7 & 3 & 6 & 3 & 1 & 1 \\
\hline Primary (1-8) & 137 & 50 & 106 & 56 & 31 & 36 \\
\hline Secondary & 86 & 31 & 51 & 27 & 35 & 41 \\
\hline TVET/College/University & 46 & 17 & 27 & 14 & 19 & 22 \\
\hline \multicolumn{7}{|l|}{ Religion } \\
\hline Muslim & 107 & 28 & 87 & 32 & 20 & 19 \\
\hline Orthodox Christian & 195 & 52 & 130 & 48 & 65 & 61 \\
\hline Other Christian (protestant, catholic etc) & 76 & 20 & 55 & 20 & 21 & 20 \\
\hline \multicolumn{7}{|l|}{ Marital status } \\
\hline Never married / Single/divorced & 12 & 3 & 8 & 3 & 4 & 4 \\
\hline Currently married or co-habiting & 366 & 97 & 263 & 97 & 103 & 96 \\
\hline \multicolumn{7}{|l|}{ Employment status } \\
\hline Not employed/house wife & 264 & 70 & 199 & 73 & 65 & 61 \\
\hline Employed & 97 & 26 & 61 & 23 & 36 & 34 \\
\hline Student & 17 & 4 & 11 & 4 & 6 & 6 \\
\hline \multicolumn{7}{|l|}{ Parity - births ever had including most recent } \\
\hline 1 & 162 & 43 & 104 & 38 & 58 & 54 \\
\hline $2-3$ & 115 & 30 & 85 & 31 & 30 & 28 \\
\hline $4+$ & 102 & 27 & 83 & 31 & 19 & 18 \\
\hline \multicolumn{7}{|l|}{ Duration between birth and interview } \\
\hline Less than a week & 73 & 19 & 29 & 41 & 44 & 11 \\
\hline $1-6$ weeks & 136 & 36 & 99 & 35 & 37 & 36 \\
\hline 7-12 weeks & 170 & 45 & 144 & 24 & 26 & 53 \\
\hline \multicolumn{7}{|l|}{ Time of birth } \\
\hline Night time & 179 & 47 & 131 & 45 & 48 & 48 \\
\hline Day time (6:00 AM-6:00 PM) & 199 & 53 & 140 & 55 & 59 & 52 \\
\hline
\end{tabular}


Table 2 Availability of Facility based Policies on Respectful Maternity Care, N=38

\begin{tabular}{|c|c|c|c|c|c|c|}
\hline \multirow[t]{2}{*}{ Availability of Policy related to RMC } & \multicolumn{2}{|c|}{$\begin{array}{l}\text { Total } \\
(n=38)\end{array}$} & \multicolumn{2}{|c|}{$\begin{array}{l}\text { Health Center } \\
(n=27)\end{array}$} & \multicolumn{2}{|c|}{$\begin{array}{l}\text { Hospital } \\
(n=11)\end{array}$} \\
\hline & $\bar{N}$ & $\%$ & $\overline{\mathrm{N}}$ & $\%$ & $\overline{\mathrm{N}}$ & $\%$ \\
\hline Freedom of movement during labor (i.e., walking around) & 38 & 100 & 27 & 100 & 11 & 100 \\
\hline Prevention of institutional violence against women and newborns & 38 & 100 & 26 & 100 & 12 & 100 \\
\hline Requirement of informed consent for procedures & 36 & 95 & 25 & 93 & 11 & 100 \\
\hline Keeping the newborn with the mother immediately after the birth & 34 & 89 & 25 & 93 & 9 & 82 \\
\hline Admission of family members/ person of choice to accompany women during labor/childbirth & 33 & 87 & 24 & 89 & 9 & 82 \\
\hline Keeping mother and baby together in the facility & 34 & 89 & 25 & 93 & 9 & 82 \\
\hline Policy of allowing non harmful cultural rituals in the facility & 27 & 71 & 23 & 85 & 4 & 36 \\
\hline Allowing women a choice of position for birth & 26 & 68 & 20 & 74 & 6 & 55 \\
\hline
\end{tabular}

Oromia and SNNP regions in Ethiopia. The four regions included in the study represent more than $86 \%$ of the total population of the country [30]. Policies of RMC at facility level that aim to improve women's experiences, including allowing a birth companion of choice, keeping newborn and mother together following childbirth, and allowing women to take their preferred birthing position were not universally observed. The observed discrepancy could be due to lack of focus by the leadership of health facilities and lack of monitoring on the policies by district and regional level health managers. A systematic review on RMC policies previously showed that such policies are feasible in low resource settings if these are prioritized [31].

Three-fourth of women interviewed reported experiencing any mistreatment. These findings are consistent

Table 3 Types of mistreatment reported by women, $N=379$

\begin{tabular}{|c|c|c|c|c|c|c|}
\hline \multirow[t]{2}{*}{ Categories } & \multicolumn{2}{|c|}{ Total } & \multicolumn{2}{|c|}{ Health center } & \multicolumn{2}{|c|}{ Hospitals } \\
\hline & $\bar{N}$ & $\%$ & $\mathrm{~N}$ & $\%$ & $\mathrm{~N}$ & $\%$ \\
\hline Any mistreatment & 281 & 74 & 188 & 69 & 93 & 87 \\
\hline Physical abuse: hit /slapped/pinched by the provider** & 7 & 2 & 5 & 2 & 2 & 2 \\
\hline $\begin{array}{l}\text { Verbal abuse: shouted at, scolded, threatened with going to } \\
\text { operating theatre, called by insulting name }\end{array}$ & 31 & 8 & 20 & 7 & 11 & 10 \\
\hline Failure to meet professional standards of care: (at least one of the 4) & 111 & 29 & 80 & 29 & 31 & 29 \\
\hline Neglect: Client left unattended when needed care at any point in stay & 39 & 10 & 28 & 10 & 11 & 10 \\
\hline $\begin{array}{l}\text { Client's request for pain medication was ignored: (among those that } \\
\text { requested it; } N=117 \text {, Health Center }=80 \text {, Hospital }=37 \text { ) }\end{array}$ & 43 & 37 & 36 & 45 & 7 & 19 \\
\hline Non-consented care: Any treatment done without women's permission** & 59 & 16 & 38 & 14 & 21 & 20 \\
\hline $\begin{array}{l}\text { Non-confidential care: At any point during Labor and childbirth stay } \\
\text { client were treated in a way that violated privacy }\end{array}$ & 24 & 6.3 & 18 & 6.6 & 6 & 5.6 \\
\hline Poor Rapport between women and providers: (at least one of the 7) & 274 & 72 & 181 & 67 & 93 & 87 \\
\hline $\begin{array}{l}\text { Poor Reception: The health workers did not greet woman when she } \\
\text { came to this facility during Labor and childbirth }\end{array}$ & 64 & 17 & 41 & 15 & 23 & 21 \\
\hline $\begin{array}{l}\text { No Explanation during labor: The health workers did not explain the } \\
\text { next steps during Labor and childbirth to clients }\end{array}$ & 181 & 48 & 154 & 43 & 44 & 41 \\
\hline $\begin{array}{l}\text { Not Responding to questions: The health workers did not respond } \\
\text { to clients' questions politely }\end{array}$ & 212 & 16 & 24 & 15 & 14 & 18 \\
\hline $\begin{array}{l}\text { Free Movement not encouraged: Health workers do not encourage } \\
\text { women to walk and change positions during Labor and childbirth }\end{array}$ & 113 & 30 & 73 & 73 & 40 & 63 \\
\hline Not Allowing Birth companion during labor & 105 & 28 & 69 & 25 & 36 & 34 \\
\hline $\begin{array}{l}\text { Birth Position of women choice was not respected: The health } \\
\text { workers did not allow women to give birth in the position they wanted } \\
\text { during Labor and childbirth }\end{array}$ & 217 & 56 & 142 & 51 & 75 & 69 \\
\hline $\begin{array}{l}\text { Food and drink not offered: After childbirth, women were not offered } \\
\text { hot drinks or food }\end{array}$ & 62 & 16 & 39 & 14 & 23 & 21 \\
\hline
\end{tabular}


Table 4 Logistic regression analysis of socio-demographic variables of women and Environmental characteristics on the reported mistreatment of women

\begin{tabular}{|c|c|c|c|c|c|c|}
\hline \multirow[b]{2}{*}{ Mistreatment } & \multicolumn{3}{|c|}{ Bi-variable } & \multicolumn{3}{|c|}{ Multivariable } \\
\hline & OR & {$[95 \% \mathrm{Cl}]$} & P-value & $\mathrm{aOR}$ & {$[95 \% \mathrm{Cl}]$} & P-value \\
\hline \multicolumn{7}{|l|}{ Age category (ref: < 25) } \\
\hline $25-34$ & 1.51 & $0.73,3.11$ & 0.266 & 1.00 & $0.47,2.13$ & 0.999 \\
\hline $35+$ & 0.68 & $0.23,2.04$ & 0.491 & 0.22 & $0.06,0.73$ & $0.014^{*}$ \\
\hline \multicolumn{7}{|l|}{ Marital status (ref: Currently married) } \\
\hline Single or divorced & 1.75 & $0.18,17.5$ & 0.633 & & & \\
\hline \multicolumn{7}{|l|}{ Parity (Ref. 1) } \\
\hline 2 to 3 & 0.62 & $0.28,1.37$ & 0.239 & 0.94 & $0.44,1.98$ & 0.867 \\
\hline $4+$ & 1.80 & $0.75,4.33$ & 0.189 & 3.36 & $1.22,9.23$ & $0.019^{*}$ \\
\hline \multicolumn{7}{|c|}{ Education level (ref: TVET/College/University.) } \\
\hline informal/no education & 1.96 & $0.05,81.71$ & 0.724 & & & \\
\hline Primary (1-8) & 1.72 & $0.41,7.26$ & 0.462 & & & \\
\hline Secondary & 0.66 & $0.16,2.67$ & 0.557 & & & \\
\hline \multicolumn{7}{|l|}{ Religion (ref: Orthodox Christian) } \\
\hline Muslim & 3.24 & $0.95,11.13$ & 0.061 & 3.30 & $1.4,7.77$ & $0.006^{*}$ \\
\hline other Christians (Prot., catholic) & 1.39 & $0.32,6.11$ & 0.662 & 1.61 & $0.63,4.09$ & 0.317 \\
\hline \multicolumn{7}{|l|}{ Facility (ref: Health center) } \\
\hline Hospitals & 9.63 & $1.25,74.26$ & 0.03 & 2.09 & $0.92,4.76$ & 0.077 \\
\hline \multicolumn{7}{|l|}{ Region } \\
\hline igray & 2.04 & $0.11,36.56$ & 0.63 & 1.21 & $0.35,4.2$ & 0.759 \\
\hline Amhara & 0.88 & $0.12,6.65$ & 0.903 & 1.67 & $0.7,4.01$ & 0.248 \\
\hline SNNPR & 0.09 & $0.01,0.7$ & 0.021 & 0.19 & $0.08,0.44$ & $<0.001^{*}$ \\
\hline \multicolumn{7}{|l|}{ Residence (ref: rural) } \\
\hline Urban & 1.26 & $0.52,3.04$ & 0.607 & & & \\
\hline \multicolumn{7}{|l|}{ ANC visits (ref. < 4) } \\
\hline $4+$ & 1.69 & $0.78,3.67$ & 0.183 & 1.26 & $0.67,2.38$ & 0.47 \\
\hline \multicolumn{7}{|c|}{ Time from childbirth to interview (ref: First week) } \\
\hline $1-6$ weeks & 0.37 & $0.12,1.12$ & 0.079 & 0.37 & $0.15,0.9$ & $0.028^{*}$ \\
\hline 7-12 weeks & 0.66 & $0.21,2.04$ & 0.470 & 0.88 & $0.35,2.21$ & 0.779 \\
\hline \multicolumn{7}{|l|}{ Childbirth time (ref. night) } \\
\hline Day time & 1.31 & $0.66,2.59$ & 0.434 & & & \\
\hline \multicolumn{7}{|c|}{ Monthly childbirth per MNH Staff (Ref. > 17) } \\
\hline Less than 17 & 5.46 & $0.97,30.62$ & 0.054 & 3.63 & $1.9,6.93$ & $<0.001^{*}$ \\
\hline \multicolumn{7}{|c|}{ MNH staff trained in BEmONC (Ref. <50\%) } \\
\hline $50 \%$ or more & 3.41 & $0.62,18.69$ & 0.157 & 1.45 & $0.75,2.82$ & 0.27 \\
\hline \multicolumn{7}{|c|}{ Policy of facility tour for pregnant women (ref. yes) } \\
\hline No & 6.74 & $1.23,37.02$ & 0.028 & 1.72 & $0.89,3.32$ & 0.11 \\
\hline \multicolumn{7}{|l|}{ Policy of anonymous (ref. yes) } \\
\hline No & 3.27 & $0.2,52.57$ & 0.402 & & & \\
\hline
\end{tabular}

* Ref: Reference group. aOR: Adjusted odds ratio, * Statistically significant at Alpha $=0.05$

with previous studies from the Ethiopian cities Addis Ababa and Bahirdar in which 78 and $67.1 \%$ of women reported disrespect and abuse respectively [21, 32]. However, our finding was higher than three other studies conducted in Ethiopia reporting 21-36\% of mistreatment based on provider-client structured observation [23, 24, 33]. 
Physical abuse was reported by only $2 \%$ women which was comparable to a study in Addis Ababa that reported $2.3 \%$ physical abuse [21] and a study in Tanzania that reported $2.7 \%$ physical abuse in exit interview [5]. Our finding was higher than a study conducted in Tigray region that reported $0.8 \%$ physical abuse [24] and a study conducted in Amhara and SNNPR regions that reported $0.5 \%$ physical abuse [33]. Our finding was lower than a previous study in the same four regions in Ethiopia that reported 9\% physical abuse using structured observation [23] and much lower than a community based study among women in Bahirdar town that reported 23.2\% physical abuse [32].

Verbal abuse was reported by $8 \%$ women which was comparable to our previous study in the same four regions in Ethiopia that reported $8 \%$ verbal abuse [23], a study in Addis Ababa that reported $7.5 \%$ insult, intermediation, threat or coercion [21] and a study in Tanzania that reported $8.7 \%$ women being shouted at [34]. But the reported level of verbal abuse was lower than a study in Bahirdar town that reported $27.1 \%$ of women reported verbal insult committed by providers [32] and a study conducted in Tigray region that reported $12.5 \%$ women being shouted at and 10.5\% women being scolded [24].

Nearly one in three women reported failure to meet professional standards of care that included being left unattended $(10 \%)$, pain relief medication being denied (37\%), non-consented care $(16 \%)$ or non-confidential care $(6.3 \%)$. Previous studies in Ethiopia did not use a comprehensive definition for failure to meet professional standard of care but different studies reported its components. The finding reported for components of failure to meet professional standards of care was consistent with a study conducted in Amhara and Oromia regions that reported $15.2 \%$ women experienced violation of privacy, $17.8 \%$ women experienced non consented care [22] and a study conducted in Tanzania that reported $8.7 \%$ women were left unattended [5]. The finding on some components were not consistent with our previous study in the four regions that reported 17\% women experienced violation of privacy and 19\% women experienced being left unattended [23] and a study in Tigray region that reported $6 \%$ women were left unattended [24].

Nearly three out of four women experienced poor rapport with providers that include poor reception of women (17\%), next steps not explained (48\%), not responding to women questions (16\%), not allowing birth companion (28\%) and not allowing women preferred birth position (56\%). The findings on poor rapport between women and providers was one of the first finding to our knowledge. Other studies assessed components of poor rapport between women and providers. The reported level of poor reception was lower than previous study in the same regions that reported 23\% women were not greeted and received politely [23]. The reported level of poor communication was higher than previous study that reported $35 \%$ women did not receive explanation about next steps [23].

Our findings show that women younger than 25 years were more likely to report mistreatment compared to those 35 years and above. This finding for younger groups of women is consistent with other studies in South Africa, Uganda and rural Australia suggesting that young women may be more likely to be mistreated or discriminated against by health providers, and sometimes blamed for getting pregnant at a younger age [26, 35-38]. It is possible however, that compared to the older age group, these women have different expectations from the health system and/or have been sensitized to respectful care to a larger extent. Older women may either have normalized the experience of mistreatment [6] or may feel barriers to report it. Muslim women were more likely to report mistreatment compared to Orthodox Christians. It is unclear whether cultural and religious expectations of Muslim women related to privacy and sex of the care provider play a role. Alternatively, Muslim women could be discriminated against by care providers. A study in Afar, Ethiopia, a predominantly Muslim community, revealed that women did not seek maternity care from health facilities because of poor services and unfriendly or even abusive treatment during childbirth [39]. A study in Ghana suggested that Muslim women did not seek maternity care from health facilities because health care providers' lack of knowledge and insensitivity to religious and cultural practices of Muslim women [40].

Women interviewed during eighth to 42 days after childbirth were less likely to report mistreatment compared to those interviewed in the first 7 days. The reason for reporting higher rates of mistreatment during the first 7 days after childbirth and lower rates after the seventh day could be due to a fresh memory of the birthing experience in the first week. Women may not have reported negative experiences for fear of reprisal by health care providers during their visit for immunization. A previous study in Tanzania in which women were interviewed in health facilities after childbirth and after a 5-10 week follow-up showed an increase in the level of mistreatment reported, considering that the follow-up interview was held at the woman's home [5].

Women with four or more previous births were more likely to report mistreatment. Discrimination of women based on parity was identified in a systematic review [26]. This finding is consistent with a study in Kenya that reported women with four to nine previous births 
being more likely to experience some form of mistreatment including non-consented care, detainment for lack of payment and being requested for bribes [25]. Facility level factors significantly associated with mistreatment of women were the number of births per MNH provider. Women interviewed in facilities with lower numbers of monthly births $(<17)$ per $\mathrm{MCH}$ provider were more likely to report mistreatment. With increasing numbers of births per $\mathrm{MNH}$ provider, the odds of reporting mistreatment decreased. This is consistent with the finding of a systematic review conducted in five African countries, which indicated that facilities with a low case load were associated with poor quality of basic maternity care services [41].

The reason for lower levels of mistreatment in facilities with relatively high numbers of births per $\mathrm{MCH}$ provider could have a causal relationship, and the other way around. In other words, high or low volume of clients could be the result of previous treatment that women experienced in these facilities, either attracting them to come or making them give birth elsewhere. However, this finding contradicts with assumptions suggesting that health providers mistreated women due to high work load. High workload was identified as a cause of negative attitudes and behavior of maternity care providers in a systematic review in low- and middle-income countries [42]. Another reason for the increase in mistreatment in facilities with lower maternity case load per provider could be the rapid expansion of these facilities since most of the new facilities usually have low case load due to preference of women for previously established facilities.

This study measured prevalence of mistreatment, using a nationally representative sample of health facilities in the four largest regions of the country. However, there are some limitations. This assessment was conducted on the premises of health facilities instead of women's homes. This may create courtesy bias, i.e. women may have provided socially desirable responses to data collectors because of fear of repercussions during postnatal care visits. To mitigate this problem, data collectors were trained to ensure privacy and confidentiality of information. Another limitation could be recall bias leading to underreporting of some of the events, since interviews were conducted within the same day to 3 months after childbirth. Those women interviewed weeks after childbirth may have forgotten some of the interactions with health providers that would have been categorized as mistreatment. However, earlier studies on birthing experiences of women reported that women remember negative experiences for long periods of time [43]. Another limitation, inherent to study design, is the fact that residual confounding variables such as unmeasured provider and facility characteristics may have affected study findings.

\section{Conclusions}

This study identified that most women experienced some form of mistreatment during childbirth in Ethiopian health facilities. Younger women, women with four or higher previous childbirths, Muslim women, women who received childbirth services in health facilities with low numbers of births per provider were disproportionately affected by mistreatment. Health workers efforts to improve respectful maternity care should consider such factors that are associated with mistreatment of women in health facilities. Health providers need to provide culturally sensitive women-centered care considering particular needs of each woman (younger versus older women) and continuously monitor experiences of women. National and regional level policy makers and program managers should investigate reasons for lower case load per provider in some health facilities so as to make appropriate corrective measures.

\section{Additional files}

Additional file 1: Exit interview tool. (PDF $589 \mathrm{~kb}$ )

Additional file 2: RMC policy assessment tool. (PDF $151 \mathrm{~kb}$ )

\section{Abbreviations \\ aOR: Adjusted Odds Ratio; BEmONC: Basic Emergency Obstetrics and Newborn Care; Cl: Confidence Interval; D\&A: Disrespect and Abuse; DE: Design Effect; MCSP: Maternal and Child Survival Program; MMR: Maternal Mortality Ratio; MNH: Maternal and Newborn Health; $\mathrm{MOH}$ : Ministry of Health; OR: Odds Ratio; RMC: Respectful Maternity Care; SNNPR: Southern Nation Nationalities Peoples Region; USAID: United States Agency for International Development}

\section{Acknowledgments}

The authors would like to acknowledge the support of colleagues from Jhpiego and Ministry of health during data collection. Finally, we would like to acknowledge the contribution of data collectors' and women who took their time to share their experience for the study team.

\section{Authors' contributions}

EDS contributed to the conceptualization, data analysis, original draft preparation and editing of the manuscript. YMK, TVA and JS contributed to the conceptualization, writing- review and editing of the manuscript. All authors read and approved the final manuscript.

\section{Funding}

This research was funded by USAID through Maternal and Child Survival Program under the terms of the Cooperative Agreement AID-OAA-A-14 -00028 .

\section{Availability of data and materials}

The datasets used during the current study is available from the corresponding author on reasonable request.

\section{Ethics approval and consent to participate}

The Johns Hopkins Bloomberg School of Public Health Institutional Review Board in Baltimore, Maryland, USA, exempted the study from oversight under U.S. legislation, 45 CFR 46.101 (b) Category (5).

Consent for publication Not applicable. 


\section{Competing interests}

The authors declare no conflict of interest. The funders had no role in the design of the study; in the collection, analyses, or interpretation of data; in the writing of the manuscript, or in the decision to publish the results.

\begin{abstract}
Author details
'Jhpiego Ethiopia, Addis Ababa, Ethiopia. ${ }^{2}$ Department of Health Sciences, University of Groningen, University Medical Centre Groningen, Global Health, Antonius Deusinglaan 1, 9713, AV, Groningen, The Netherlands. ${ }^{3} \mathrm{Jhpiego}$, Baltimore, USA. ${ }^{4}$ Department of Obstetrics and Gynecology, Leiden University Medical Center, Leiden, The Netherlands. ${ }^{5}$ Department of Obstetrics and Gynecology, Leeuwarden Medical Center, Henri Dunantweg 2, 8934, AD, Leeuwarden, The Netherlands.
\end{abstract}

Received: 14 January 2019 Accepted: 25 July 2019

Published online: 27 August 2019

\section{References}

1. Sustainable Development Goals. https://sustainabledevelopment.un.org/ topics/sustainabledevelopmentgoals.

2. Campbell OM, Calvert C, Testa A, Strehlow M, Benova L, Keyes E, Donnay F, Macleod D, Gabrysch S, Rong L, et al. The scale, scope, coverage, and capability of childbirth care. Lancet (London, England). 2016;388(10056):2193-208.

3. The prevention and elimination of disrespect and abuse during facility -based childbirth: WHO statement. http://apps.who.int/iris/bitstream/1 0665/134588/1/WHO_RHR_14.23_eng.pdf. Accessed 24 Dec 2018.

4. D'Oliveira, Diniz S. Violence against women in health-care institutions: an emerging problem. Lancet (London, England). 2002;9318:16815(May 10):359.

5. Kruk ME, Kujawski S, Mbaruku, Ramsey WK. Disrespectful and abusive treatment during facility delivery in Tanzania: a facility and community survey. Health Policy Plan. 2014:1-8.

6. Bowser $\mathrm{H}$. Exploring evidence for disrespect and abuse in facility-based childbirth: Report of a landscape analysis USAID; 2010.

7. Shiferaw S, Spigt M, Godefrooij M, Melkamu Y, Tekie M. Why do women prefer home births in Ethiopia? BMC Pregnancy Childbirth. 2013;13:5.

8. Bohren MA, Hunter EC, Munthe-Kaas HM, Souza JP, Vogel JP, Gulmezoglu AM. Facilitators and barriers to facility-based delivery in low- and middle-income countries: a qualitative evidence synthesis. Reprod Health. 2014;11(1):71.

9. Tebekaw $Y$, James Mashalla Y, Thupayagale-Tshweneagae G. Factors influencing Women's preferences for places to give birth in Addis Ababa, Ethiopia. Obstet Gynecol Int. 2015;2015:439748.

10. Aragaw A, Yigzaw T, Tetemke D, G/Amlak W. Cultural competence among maternal healthcare providers in Bahir Dar City Administration, Northwest Ethiopia: cross sectional study. BMC Pregnancy Childbirth. 2015;15:227.

11. World Health Organization (WHO). Trends in maternal mortality: 1990 to 2013. Estimates by WHO, UNICEF, UNFPA, the World Bank and the World Bank. Geneva: WHO; 2014.

12. Ethiopian Public Health Institute $E$, Federal Ministry of Health Addis Ababa E, Averting Maternal Death and Disability (AMDD) U. Ethiopian Emergency Obstetric and Newborn Care (EmONC) Assessment 2016. 2017.

13. FMOH U, UNFPA W. AMDD. National Baseline Assessment for emergency obstetric and newborn care: Ethiopia, 2008. Addis Ababa: The Ethiopian federal Ministry of health Google Scholar; 2009.

14. Helath sector Transformation Plan 2015-2020. http://www.moh.gov.et/home/-/ asset_publisher/Mfl2/content/ethiopia-s-five-year-health-sector-transformationplan-2008-2012-efy-2015-16-2019-20-. Accessed 24 Dec 2018.

15. Health Sector Development Programme III Annual Performance Report EFY 2002 (2009/10). 2011.

16. ANNUAL PERFORMANCE REPORT EFY 2009 (2016/17). 2018.

17. Basic Emergency Obstetric \& Newborn Care (BEmONC). Training Manual. http://pdf.usaid.gov/pdf_docs/PA00JX4F.pdf. Accessed 24 Dec 2018.

18. Burrowes S, Holcombe SJ, Jara D, Carter D, Smith K. Midwives' and patients' perspectives on disrespect and abuse during labor and delivery care in Ethiopia: a qualitative study. BMC Pregnancy Childbirth. 2017;17(1):263.

19. Bohren. Facilitators and barriers to facility-based delivery in low- and middle-income countries: a qualitative evidence synthesis globally: a mixed -methods systematic review. PLoS Med. 2014;6(e1001847):12.

20. Mane P. Some thoughts on disrespect and abuse in childbirth in response to FIGO's mother-baby friendly birthing facilities initiative. Int J Gynaecol Obstet. 2015;130(2):115.
21. Asefa A, Bekele D. Status of respectful and non-abusive care during facility -based childbirth in a hospital and health centers in Addis Ababa, Ethiopia. Reprod Health. 2015;12:33.

22. Banks KP, Karim AM, Ratcliffe HL, Betemariam W, Langer A. Jeopardizing quality at the frontline of healthcare: prevalence and risk factors for disrespect and abuse during facility-based childbirth in Ethiopia. Health Policy Plan. 2017:6-7.

23. Sheferaw ED, Bazant E, Gibson H, Fenta HB, Ayalew F, Belay TB, Worku MM, Kebebu AE, Woldie SA, Kim YM, et al. Respectful maternity care in Ethiopian public health facilities. Reprod Health. 2017;14(1):60.

24. Gebremichael MW, Worku A, Medhanyie AA, Berhane Y. Mothers' experience of disrespect and abuse during maternity care in northern Ethiopia. Glob Health Action. 2018;11(sup3):1465215.

25. Abuya T, Warren CE, Miller N, Njuki R, Ndwiga C, Maranga A, Mbehero F, Njeru A, Bellows B. Exploring the prevalence of disrespect and abuse during childbirth in Kenya. PLoS One. 2015;10(4):e0123606.

26. Bohren MA, Vogel JP, Hunter EC, Lutsiv O, Makh SK, Souza JP, Aguiar C, Saraiva Coneglian F, Diniz AL, Tuncalp O, et al. The Mistreatment of Women during Childbirth in Health Facilities Globally: A Mixed-Methods Systematic Review. PLoS Med. 2015;12(6):e1001847.

27. MCHIP. Evaluation of the effects of standards-based management and recognition (SBM-R) intervention on the quality of maternal and newborn health Care Services in Ethiopia in. Addis Ababa. 2015.

28. Sampling manual for facility survey-series no.3: MEASURE evaluation; 2001.

29. StataCorp. 2017. Stata Statistical Software: Release 15. College Station TSL. In.

30. Commission PC: Summary and Statistical Report of the 2007 population and Housing Census In. Addis Ababa; 2008.

31. Downe $\mathrm{S}$, Lawrie TA, Finlayson $\mathrm{K}$, Oladapo OT. Effectiveness of respectful care policies for women using routine intrapartum services: a systematic review. Reprod Health. 2018;15(1):23.

32. Wassihun B, Deribe L, Worede N, Gultie T. Prevalence of disrespect and abuse of women during child birth and associated factors in Bahir Dar town, Ethiopia. Epidemiology and health. 2018;40:e2018029.

33. Banks KP, Karim AM, Ratcliffe HL, Betemariam W, Langer A. Jeopardizing quality at the frontline of healthcare: prevalence and risk factors for disrespect and abuse during facility-based childbirth in Ethiopia. Health Policy Plan. 2018:33(3):317-27.

34. Freedman LP, Kruk ME. Disrespect and abuse of women in childbirth: challenging the global quality and accountability agendas. Lancet (London, England). 2014;384(9948):e42-4.

35. Ishola F, Owolabi O, Filippi V. Disrespect and abuse of women during childbirth in Nigeria: a systematic review. PLoS One. 2017;12(3):e0174084.

36. Atuyambe L, Mirembe F, Johansson A, Kirumira EK, Faxelid E. Experiences of pregnant adolescents-voices from Wakiso district, Uganda. Afr Health Sci. 2005;5(4):304-9.

37. Jewkes R, Abrahams N, Mvo Z. Why do nurses abuse patients? Reflections from south African obstetric services. Soc Sci Med. 1998;47(11):1781-95.

38. Dietsch E, Shackleton P, Davies C, McLeod M, Alston M. You can drop dead': midwives bullying women. Women and birth. 2010;23(2):53-9.

39. King R, Jackson R, Dietsch E, Hailemariam A. Barriers and facilitators to accessing skilled birth attendants in Afar region, Ethiopia. Midwifery. 2015;31(5):540-6.

40. Ganle JK. Why Muslim women in northern Ghana do not use skilled maternal healthcare services at health facilities: a qualitative study. BMC Int Health Hum Rights. 2015;15:10.

41. Kruk ME, Leslie HH, Verguet S, Mbaruku GM, Adanu RMK, Langer A. Quality of basic maternal care functions in health facilities of five African countries: an analysis of national health system surveys. Lancet Glob Health. 2016;4(11):e845-55.

42. Mannava P, Durrant K, Fisher J, Chersich M, Luchters S. Attitudes and behaviours of maternal health care providers in interactions with clients: a systematic review. Glob Health. 2015;11:36.

43. Takehara K, Noguchi M, Shimane T, Misago C. A longitudinal study of women's memories of their childbirth experiences at five years postpartum. BMC Pregnancy Childbirth. 2014;14:221.

\section{Publisher's Note}

Springer Nature remains neutral with regard to jurisdictional claims in published maps and institutional affiliations. 